\title{
Os custos de produção e a rentabilidade da soja nos municípios de Santarém e Belterra, estado do Pará
}

\author{
Cyntia Meireles de OLIVEIRA ${ }^{1}$, Antônio Cordeiro de SANTANA², Alfredo Kingo Oyama HOMMA ${ }^{3}$ \\ RESUMO \\ O artigo teve por objetivo analisar os custos de produção da soja, nos municípios de Santarém e Belterra, considerando que, \\ este é um critério competitivo básico para determinar a eficiência operacional, bem como para a formação de vantagens \\ competitivas sustentáveis. Para tanto, a análise foi realizada a partir da percepção de 20 produtores sobre os conceitos e aplicação \\ dos custos fixos e variáveis, utilizados nas decisóes de produzir. Entre os produtores, 18 utilizam tecnologia mecânica e de \\ insumos modernos, porém não empregam práticas conservacionistas. Também não computam grande parte dos custos fixos \\ para determinar o lucro, um indicador de desempenho competitivo. As unidades de produçáo com produtividade de até 2.400 \\ $\mathrm{kg} \mathrm{ha}^{-1}$ (40 sacas de $60 \mathrm{~kg} \mathrm{ha}^{-1}$ ) estáo tendo prejuízo. Por outro lado, os agricultores que utilizam tecnologias conservacionistas, \\ como o plantio direto, estão gerando lucro. Finalmente, conclui-se que, $80 \%$ dos sistemas de produção de grãos que utilizam \\ tecnologia tradicional não são sustentáveis na região estudada e têm maiores custos de produção.
}

PALAVRAS-ChaVE: Produtividade; receita líquida; soja na Amazônia.

\section{The cost of production and profitability of soybeans in the municipalities of Santarém and Belterra, State of Pará}

\section{ABSTRACT}

The paper aimed to analyze the production costs of soybeans in the municipalities of Santarém and Belterra, considering that this is a competitive basic criterion for determining the operational efficiency as well as the formation of sustainable competitive advantage. The analysis was based on the perception of 20 producers on the concepts and application of fixed and variable costs used in decisions to produce soybean. The results showed that 18 producers use mechanical technology and modern inputs, but do not employ conservation practices. They also do not compute much of the fixed costs to determine profit, an indicator of competitive performance. The production units with productivity of up to 2,400 kg ha-1 (40 bags of $\left.60 \mathrm{~kg} \mathrm{ha}^{-1}\right)$ are not having profit. On the other hand, farmers who use conservation technologies like direct-planting are getting profit. Finally, we conclude that, $80 \%$ of the grain production systems using traditional technology are not sustainable in the region studied and have high production cost .

KEYWORDS: Productivity; net income; Amazon soybean.

\footnotetext{
1 Universidade Federal Rural da Amazônia (UFRA). Avenida Presidente Tancredo Neves, 2501. Bairro: Montese. CEP: 66077-901. Belém-Pará. E-mail: cyntiamei@hotmail.com. 2 Universidade Federal Rural da Amazônia (UFRA). Avenida Presidente Tancredo Neves, 2501. Bairro: Montese. CEP: 66077-901. Belém-Pará. E-mail: acsantana@superig.com.br. ${ }^{3}$ Empresa Brasileira de Pesquisa Agropecuária (EMBRAPA) Amazônia Oriental. Travessa Dr. Enéas Pinheiro s/n. Caixa Postal 48. CEP: 66095-100. Belém-Pará. E-mail: homma@ cpatu.embrapa.br.
} 


\section{INTRODUÇÃO}

A produção de grãos (arroz, milho e soja) nos municípios de Santarém e Belterra é praticada em unidades de produção que utilizam mecanização, adubos químicos e corretivos de solo, bem como defensivos para o controle de pragas, doenças e ervas daninhas. $\mathrm{O}$ emprego de técnicas agronomicamente sustentáveis como o plantio direto existe, mas é raro, assim como, também, é inicial a utilização das técnicas da agricultura de precisão.

Os municípios de Santarém e Belterra foram eleitos para este estudo, em função de formarem um epicentro produtivo recente, onde estáo localizadas as unidades de produção, agroindústrias beneficiadoras de grãos e a multinacional Cargill Agrícola S.A. (Cargill). A despeito dos municípios de Santarém e Belterra formarem um dos principais epicentros produtivos de grãos do estado do Pará, ainda não há estudos sistematizados sobre o desempenho da atividade de grãos na BR-163, considerando que, a análise de custos é um dos principais fatores determinantes dessa competitividade. Dessa feita, a presente pesquisa pode contribuir para esclarecer sobre o processo de decisáo dos produtores, o retorno obtido com as tecnologias em uso, bem como para orientar a política de fomento e comercializaçáo da produção de grãos nesta regiấo.

No geral, os produtores tomam decisão de forma isolada e, sobretudo os produtores de soja, que dependem fortemente do fornecimento de insumos e da venda do produto para a Cargill, que opera com poder de monopsônio. Sendo assim, dada a atomização dos produtores, o mercado do produto opera com características próximas da concorrência perfeita. Logo, o controle dos custos e aumento da produtividade da lavoura são os fatores que os produtores monitoram, em busca de obterem lucro a curto prazo.

O controle dos custos, portanto, continua sendo um critério competitivo básico para determinar a eficiência operacional, e para a formação de vantagens competitivas sustentáveis (Santana 2003). Neste sentido, conforme Santana (2007), nos estágios iniciais de evolução dos aglomerados industriais, principalmente, os custos de produção devem ser vistos como fonte de vantagem competitiva empresarial. Dentre as formas de se conseguir reduzir custos, citam-se: os ganhos de escala; qualificação de mão de obra; localização estratégica da empresa em relação ao mercado; utilização de inovaçóes tecnológicas no produto, no processo e, ou, na gestão e; integração vertical e horizontal. Estes fatores permitem alcançar o nível ótimo da produção, considerando, conforme Santana et al. (2007) e Pindyck e Rubinfeld (2010), aquele em que o custo médio é o mais baixo e corresponde ao tamanho ótimo da firma competitiva.

Para Santana (2007), em termos de objetivos de crescimento empresarial, tem-se o lucro como medida de desempenho, por isso as empresas combinam alternativas de desempenho, visando à obtençáo de taxas de lucro satisfatórias. Para Santana (2007), "A teoria da administração é, particularmente, a teoria da racionalidade limitada - o comportamento dos indivíduos se volta para a satisfação porque eles náo possuem a capacidade de maximizar". Nestes termos, as empresas operam com a expectativa de obterem lucros futuros superiores ao obtido no presente. Considerando que o preço da soja, na área de estudo, é estabelecido pela Cargill Agrícola S.A. (Cargill), uma vez que é a única empresa que compra soja, a questão principal está em aumentar a produtividade via implementação de inovações, e reduzir seus custos de produção. Por seu turno, a obtençáo de lucros é o motivo dominante na tomada de decisão empresarial e a força fundamental que explica a trajetória de crescimento das unidades produtivas de grãos no local (Santana 2007).

Embora o lucro seja o principal objetivo dos produtores de grãos, os custos computados por eles são enviesados para menos, pois não incorporam todos os custos fixos para análise a curto prazo. Isto significa que, mesmo para os produtores que sinalizam estar obtendo lucro, isto pode apenas ser uma ilusão, uma vez que, grande parte dos custos fixos não está sendo considerada no cômputo dos seus custos totais. Portanto, cabe a questâo: os produtores de grãos dos municípios de Santarém e Belterra estáo efetivamente obtendo lucro, ou apenas cobrindo os custos variáveis e uma parcela dos custos fixos?

Para responder a esta questão, o objetivo do trabalho foi investigar, na percepçấo dos produtores de grãos dos municípios de Santarém e Belterra, a estrutura de custos de produção de grãos, principalmente soja, que consideram na sua tomada de decisão e que efetivamente utilizaram para a formação dos preços do produto na safra de 2008.

\section{MATERIAL E MÉTODOS}

A análise realizada neste estudo é descritiva e explicativa, conforme Santana et al. (2005) e Santana et al. (2006), pois além da identificação da existência de relação entre as variáveis, discute-se a natureza dessa relação, ao analisar os elementos considerados importantes e determinantes na constituiçáo dos custos de produção (preço dos insumos e dos produtos, mão de obra, frete, arrendamento de terra, aluguel de máquinas, produção, área colhida).

Os dados básicos utilizados neste trabalho foram obtidos com a aplicação de questionários específicos, entre os meses de junho a agosto de 2008, preenchidos a partir de informaçôes disponibilizadas por 20 produtores de grãos, que possuem propriedades ou arrendamentos nos municípios de Belterra e Santarém. A amostra foi intencional (não probabilística), extraída entre os 160 produtores cadastrados na Cargill, que também foi entrevistada para informar sobre as condiçôes 
gerais do mercado local. Os entrevistados, para atender aos objetivos da pesquisa, foram selecionados com base no cadastro do Sindicato dos Produtores Rurais de Santarém (SIRSAN), visando eleger aqueles que representam o universo dos produtores de grãos (arroz, milho e soja) em relação ao tempo na regiáo, tecnologia de produçáo, tamanho da área e localizaçáo da área de produção nos dois municípios.

Os dados referentes aos custos de produçáo foram originários de informações primárias obtidas in loco, além da utilização das bases do Agrianual (2009) e da Companhia Nacional de Abastecimento (Conab 2010), utilizados como indicativo de que essa tecnologia, independentemente da regiấo produtora onde é utilizada, tende reproduzir resultados similares quanto ao desempenho da produção de soja.

\section{Custos de produção}

Os custos totais $(C T)$ envolvidos na produção são a soma dos custos fixos totais (CFT) e dos custos variáveis totais $(C V T)$, especificados como na equação abaixo:

$$
C T_{q}=C F T_{q}+C V T_{q}=\sum_{i=1}^{n} p_{i} x_{i}+\sum_{j=1}^{m} p_{j} x_{j}
$$

Em que $p_{i}$ é o preço do i-ésimo insumo fixo utilizado na produção (juros, aluguel, depreciação, manutenção, seguro, arrendamento de terra, remuneração do produtor, etc.), $x_{i}$ é a quantidade do i-ésimo insumo fixo; $p_{j}$ é o preço do j-ésimo insumo variável utilizado na produçâo (sementes, adubos, pesticidas, combustível, mão de obra, impostos, etc.), $x_{j}$ é a quantidade do j-ésimo insumo variável.

O custo total médio (CTMe) deve ser levado em consideração na tomada de decisão sobre o que, quanto e como produzir, por facilitar a percepção dos agentes, é obtido pela razão entre estes custos e a produção total $\mathrm{Q}$, como na equação abaixo (Pyndick e Rubinfeld 2010):

$$
C \mathrm{CMe}_{q}=\frac{C T_{q}}{Q}=\frac{C F T_{q}}{Q}+\frac{C V T_{q}}{Q}=C F M e_{q}+C V M e_{q}
$$

A receita total $(R T)$, obtida com a venda da produção é dada pela quantidade produzida vezes o preço recebido pelo produtor em nível da unidade de produçấo. A Fórmula para um produto específico $\mathrm{Q}$ é dada por:

$$
R T_{q}=P_{q} \cdot Q_{q}
$$

O lucro total $(L)$ obtido da produçáo de um produto específico é dado pela diferença entre a receita total $(R T)$ e o custo total $(C T)$, ou seja:

$$
L_{q}=R T_{q}-C T_{q}
$$

Se o preço unitário do produto for maior que o custo total médio $(C T M e=V F M e+C V M e)$, a empresa obtém lucro no curto prazo, e se for menor que o CTMe, terá prejuízo. Assim, o lucro unitário (ou lucro por saca de $60 \mathrm{~kg}$ ou por hectare) é igual a $(P-C T M e)$ e o lucro total é dado por:

$$
L=(P-C T M e) \cdot Q
$$

Em que: $\mathrm{L}=$ lucro por unidade $\left(\mathrm{R} \$ \mathrm{ha}^{-1}\right.$ ou $\mathrm{R} \$$ por quantidade de sacas de $60 \mathrm{~kg}$ de soja por hectare); $\mathrm{P}=$ preço unitário do produto $(\mathrm{R} \$ 1.000 \mathrm{~kg}$ ou $\mathrm{R} \$$ por sacas de 60 $\mathrm{kg}$ ); $\mathrm{Q}=$ quantidade produzida por hectare ou expresso em números de $1.000 \mathrm{~kg} \mathrm{ha}^{-1}$ (ou sacas de $60 \mathrm{~kg} \mathrm{ha}^{-1}$ ).

\section{RESULTADOS E DISCUSSÃO}

\section{Contexto geral da análise}

Com base nos resultados, tem-se que $70 \%$ dos produtores entrevistados estão na atividade há mais de cinco anos. Destes 14 produtores, 10 participam, desde o início, da formação do Arranjo Produtivo Local (APL) de grãos dos municípios de Santarém e Belterra. Entre as unidades de produção, 12 empregam até nove pessoas, o que as caracteriza como micronegócios, sendo que, destes trabalhadores, 22,5\% são contratados temporariamente e $31,5 \%$ são assalariados permanentes, recebendo entre um a cinco salários mínimos, e que, cerca de $70 \%$ náo possuem o ensino fundamental, ou o ensino médio, completo. Conforme dados da pesquisa, esta mão de obra representa, em média, cerca de $6 \%$ dos custos totais de produção.

Apenas 7,5\% do total de entrevistados contrataram serviços técnicos e, ou, consultores para orientar a produção de grãos, de modo que os custos com serviços técnicos especializados são restritos a uma pequena parcela dos produtores do APL. Dentre os produtores que contrataram serviços especializados, citam-se aqueles com área de produção acima de 1.000 hectares, utilizam inovaçóes tecnológicas modernas como o plantio direto e agricultura de precisão e, por isso, necessitam de técnicos para gerir suas propriedades. Estes técnicos, segundo informaçốes colhidas, estâo recebendo entre dez e vinte salários mínimos, além de premiaçôes com base no aumento de produtividade alcançado no ano. Contudo, isto constitui exceção no âmbito dos produtores entrevistados no APL de Grãos em Santarém e Belterra, pois, a grande parte das unidades produtivas ( $90 \%$ do total) cultiva entre $200 \mathrm{e}$ 500 hectares, portanto, não geram renda suficiente para pagar os serviços técnicos especializados.

Os produtores de grãos estão localizados, geograficamente, em uma regiáo onde o ativo terra tinha valor monetário muito baixo relativamente às regiôes produtoras de gráos do Maranhão e Mato Grosso até poucos anos atrás (Agrianual 2009), o que contribuiu para as unidades produtivas atuarem com vantagem comparativa da abundância deste recurso natural e vantagem competitiva na produção de grãos, por 
terem os custos de produçáo mais baixos. Com o passar do tempo, a entrada de outros produtores na atividade, fez com que o valor do ativo terra se elevasse e, diluísse a vantagem competitiva apropriada pelos produtores pioneiros.

A agricultura mecanizada de Belterra e Santarém contribuiu para o processo de valorização fundiária, gerando exigências mínimas para a entrada de novos investidores na área, além de ter forçado os agricultores familiares a venderem suas terras e a se deslocarem para novas áreas de floresta, ou mesmo, para os centros urbanos. Esta informaçáo foi constatada em pesquisa realizada por Santana et al. (2006), ao destacar que, entre 2000 e 2005, 90\% das áreas do entorno da BR-163 mudaram de proprietário, em especial, no trecho entre Santarém e Belterra. Conforme Santana et al. (2006), em 2000, o preço da terra era cotado, em média, a $\mathrm{R} \$ 50,00$ ha ${ }^{-1}$, passando para $\mathrm{R} \$ 100,00 \mathrm{ha}^{-1}$, em 2002 , e chegando, em 2004, a R \$2.500,00 ha ${ }^{-1}$. Em 2008, o preço médio de venda de terras, conforme obtido na pesquisa de campo, atingiu o patamar de R\$4.443,33 ha ${ }^{-1}$. Certamente, o aumento do valor da terra se deve à grande procura, em função das condiçôes de infraestrutura de comercialização (porto da Cargill em Santarém), e ao esgotamento das terras planas nas proximidades da BR-163.

Dentre as vantagens locacionais intrínsecas à operacionalização no pólo de grãos de Santarém e Belterra, $90 \%$ dos produtores citou as facilidades em escoar o produto, dada a proximidade do porto graneleiro de Santarém. De acordo com a Cargill, enquanto os produtores dos municípios de Sinop e Sorriso, em Mato Grosso, pagam até R\$ 150,00 por $1.000 \mathrm{~kg}$ de frete até ao Porto de Santarém, os produtores da região pagam, em média, $R \$ 15,00$ por $1.000 \mathrm{~kg}$ constituindo uma vantagem competitiva locacional de custo do produto para os produtores de Santarém e Belterra.

Por outro lado, parte desta vantagem é subtraída pelo custo do frete do insumo, que vem de outras regiôes. Este fato foi reconhecido por $75 \%$ dos produtores entrevistados, destacando o elevado custo do transporte dos insumos. Um produtor, que também é revendedor local de insumos, destacou que, o custo do frete de $1.000 \mathrm{~kg}$ de insumo, do porto de Barcarena à Santarém, é de R\$160,00. Este custo é quase o dobro do que se paga nos municípios de Sinop e Sorriso do Mato Grosso, pelo frete rodoviário do insumo. Como decorrência, este custo foi relatado como muito alto por $30 \%$ dos produtores entrevistados. Finalmente, este é um item de custo variável de suma importância para a condução das lavouras de grãos, pois envolve adubos, defensivos e sementes, principalmente.

$\mathrm{O}$ ciclo de produção anual dos grãos tem início com o plantio do arroz, ou do milho, no período de dezembro até a primeira quinzena de janeiro. A colheita é realizada no período de março até meados de abril. No caso da cultura do arroz, sua safra coincide com as de Goiás e Rio Grande do Sul (Santana et al. 2006).

Como a soja exige maior nivelamento do terreno, o arroz é introduzido primeiro na rotação de culturas, sendo que seus custos de preparo de área e plantio equivalem a quase 50\% do custo unitário de produção em área mecanizada. A função do arroz é de "amansar a terra" para a soja, visto que o milho, conforme Santana et al. (2005), tem mercado restrito na região, dependendo, quase que exclusivamente, da capacidade de absorção da agroindústria de aves de postura de Santarém. Normalmente, a soja é introduzida entre a última quinzena de abril até meados de maio, e a colheita ocorre no final de julho e, durante todo o mês de agosto, coincidindo com a entressafra dos estados do Mato Grosso e do Rio Grande do Sul.

Quanto aos custos fixos, destaca-se seu maior valor na soja, em relação ao milho e ao arroz, já que a mecanização da soja é utilizada em todas as práticas culturais: preparo de área, plantio, tratos culturais e colheita (Santana et al. 2006), cujo valor pode chegar até três vezes mais que nos cultivos mecanizados do arroz. A mecanizaçáo corresponde a $20 \%$ do custo total médio de produção de soja, mas tende a diminuir à medida que a escala aumenta (Conab 2010). Trata-se de uma tecnologia mais intensiva no uso de capital e da terra, do que no uso de mão de obra.

A despeito dos custos variáveis também serem altos para a cultura da soja, devido à utilizaçáo de adubos e defensivos, a instalação das indústrias de fornecimento de calcário nos municípios de Monte Alegre e Itaituba, causaram um impacto positivo por reduzir o seu custo, pois o preço médio de $\mathrm{R} \$$ 150,00 por $1.000 \mathrm{~kg}$, em 2000 , para $\mathrm{R} \$ 20,00$ por $1.000 \mathrm{~kg}$, em 2005 (Santana et al. 2006).

$\mathrm{O}$ número de fornecedores com que os produtores se relacionam náo passa de cinco, para $90 \%$ dos entrevistados, sendo que, o preço dos insumos e as condiçóes de pagamento são levados em consideraçấo na seleçấo dos mesmos, para $25 \%$ e $17 \%$ dos produtores, respectivamente. Estes dados evidenciam que os produtores utilizam como critério de seleção das empresas fornecedoras de insumos, apenas o preço e a condiçáo de pagamento, já que, os custos variáveis têm uma considerável importância na composição dos custos totais de produção de grãos.

Além disso, 35\% dos entrevistados enfrentam dificuldades para adquirir maquinário. Note-se que mais de $75 \%$ dos produtores possuem máquinas de seis a mais de dez anos de uso, o que indica sucateamento da frota de máquinas e equipamentos. Apenas um produtor, dentre os entrevistados, possui um trator com menos de dois anos. O aumento dos custos, aliado a menores margens em relação aos custos variáveis, contribui para que cerca de $50 \%$ dos produtores tenham dificuldades em pagar juros de empréstimo. 


\section{Análise dos custos}

A realização de lucro é o principal objetivo da firma, independentemente da estratégia utilizada. As empresas rurais, em funçáo da alta instabilidade da receita bruta total, devido à inelasticidade preço da oferta e as flutuaçōes dos preços, têm no objetivo da sobrevivência a longo prazo, a explicação para a compreensão do seu comportamento. Estas empresas, portanto, operam com características próximas da concorrência perfeita, em função dos seguintes pontos principais (Pindyck e Rubinfeld 2010):

O produto é homogêneo na percepção dos compradores de gráos, uma vez que uma saca de $60 \mathrm{~kg}$ de soja comercializada por um produtor é idêntica aquelas ofertadas pelos demais produtores (são substitutos perfeitos, portanto, não há preferências específicas por um produto de um dado fornecedor, em dado local);

Grande número de produtores e consumidores, cada qual transacionando uma pequena parcela do volume do total de grãos do mercado. Os produtores são tomadores de preços, pois suas decisóes individuais não influenciam o preço de equilíbrio do mercado de grãos;

O fluxo de informaçôes sobre preço, custo operacional de produçáo e transporte são do conhecimento dos principais agentes do mercado (empresas, produtores locais, intermediários), assim como mobilidade de fatores (mão de obra) entre os produtores locais de grãos, em resposta a novas oportunidades de extração ou plantio do produto;

Não existem fortes barreiras econômicas à entrada e à saída dos agentes do mercado de grãos da área de estudo a qualquer tempo;

Os custos fixos são irrecuperáveis, portanto, depois da tomada de decisão sobre a utilização de tais custos, eles passam a incidir sobre a produçáo, independente do seu nível de utilização. Estes custos devem ser pensados a longo prazo, tendo em vista a trajetória de crescimento da unidade de produção. Os custos variáveis, por seu turno, estáo diretamente atrelados ao nível da produção. Estes custos, geralmente, são percebidos pelos produtores e causam maior preocupação no ajuste da quantidade a ser produzida, de tal forma que, pelo menos tais custos sejam cobertos a curto prazo;

De forma mais específica, tendo em vista as operaçóes de rotina dos produtores, as decisóes foram pensadas em termos unitários. Assim, é razoável que o produtor saiba o preço a ser pago por cada unidade do produto posto a venda e, por consequência, o custo de produção desta unidade de produto, que pode ser uma saca de $60 \mathrm{~kg}$, no caso da produçấo de grãos. Isto significa dizer que, em tese, o produtor compara o preço recebido por uma unidade do produto com o custo realizado na produçấo (neste ponto, é necessário cuidado, pois, muitos produtores raciocinam apenas em termos dos custos variáveis e não dos custos totais, portanto, podem ter uma ilusão quanto ao lucro real). Se o resultado for positivo, tem-se lucro e, se for negativo, prejuízo. $\mathrm{Na}$ atividade rural, é comum ouvir do produtor a seguinte frase: "estou apenas empatando este ano", ou "este ano náo deu nem se quer para empatar". Com isto, os produtores estáo informando que os preços do produto apenas compensam os custos de produçáo, no primeiro caso, ou estấo tomando prejuízo, no segundo caso;

Sendo assim, apresenta-se a situaçáo teórica para a operação da empresa rural diante das condiçóes de lucro, ou de prejuízo, assim como, na posição de contribuição para recuperar os custos fixos, a curto prazo. Isto é possível, por meio da análise das curvas de custos médios e marginal.

A obtenção de lucro máximo, ou de prejuízo, pela empresa rural, na ótica da teoria neoclássica, depende da relação entre o preço do produto e o custo médio total, em nível da unidade de produçáo, ponto em que, conceitualmente, a receita marginal se iguala ao custo marginal $(R M a=C M a)$. $\mathrm{A}$ $R M a$ é o incremento à receita total, gerado com a produçáo de uma unidade adicional (no caso da pesquisa $R M a=$ $P=C M a$, uma vez que náo se pretende ilustrar apenas a situação de máximo lucro), equiparando-se ao $C M a$, que é o incremento de custo necessário para a obtençáo dessa unidade de produção (Santana et al. 2005; Nikerson e Zenger 2008; Varela e Santana 2009).

$\mathrm{Na}$ Figura 1, ilustram-se as curvas de CTMe, CVMe e custo marginal $(C M a=d C / d Q)$. De acordo com a teoria neoclássica sobre a concorrência perfeita (Pindyck e Rubinfeld 2010), as curvas de CTMe e CVMe apresentam a forma de "U" e a curva de $C M a$, na sua parte ascendente, cruza tais curvas em seus pontos de mínimo. Nesta figura, a produção

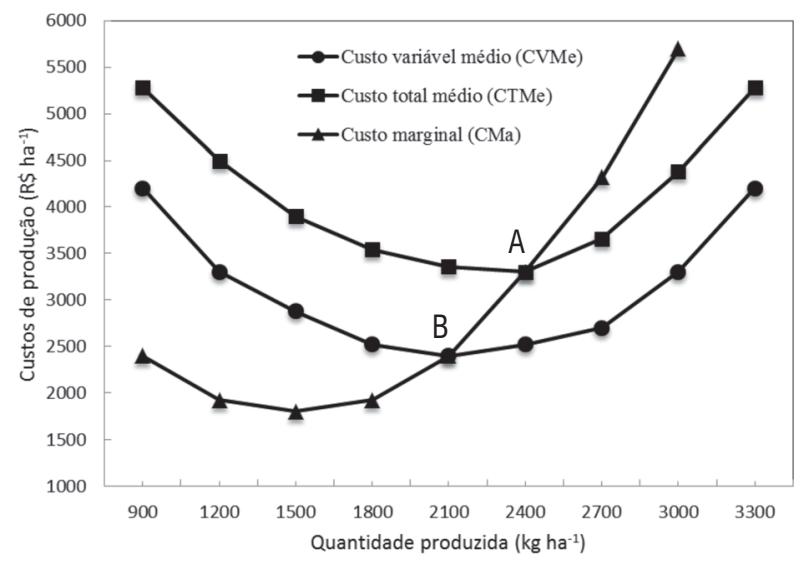

Figura 1 - Custo total médio - CTMe (círculo cheio), custo variável médio CVMe (quadrado cheio) e custo marginal - $\mathrm{CMa}$ (triangulo cheio) em função da quantidade de soja produzida. Ponto A: Custo marginal é igual ao custo variável médio mínimo e indica que apenas os custos variáveis são cobertos; Ponto B: 0 custo marginal é igual ao custo total mínimo e indica que o lucro é igual a zero. Fonte: Elaborada pelos autores com base na pesquisa de campo. 
de $2.700 \mathrm{~kg}$ (ou 45 sacas de $60 \mathrm{~kg}$ ) de soja por hectare serve de ilustração da escala ótima de produçáo, pois, a esse nível de produtividade, obtém-se o menor custo unitário por cada hectare de soja cultivado.

Neste contexto, a análise específica de curto prazo pode identificar produtores operando em diversas posiçôes da relação entre o preço e o $C T M e$, e entre o preço e o $C V M e$. Como ilustrado na Figura 1, a situação A mostra que o lucro de curto prazo é zero $(P=C T M e$ ou $L=P-C T M e=0)$ e, na situação $\mathrm{B}(P=C V M e$ ou $L=P-C T M e<0)$, assumindo que os preços se igualam aos custos exatamente nestes pontos, a empresa encontra-se com prejuízo no curto prazo. Nesta situaçáo, a receita total teria de ser igual a $2.700 \mathrm{~kg}$ (ou 45 sacas de $60 \mathrm{~kg}$ ) de soja para cobrir os custos totais. Se os preços permitirem gerar um valor equivalente para gerar uma receita maior do que este, tem-se um lucro positivo, em caso contrário, se a receita for menor, tem-se prejuízo.

$\mathrm{O}$ adequado para o produtor seria a situação em que o preço é maior do que o CTMe $(L=P-C T M e>0)$, ou seja, estaria operando no ramo da curva de custo marginal acima do ponto A, com lucro positivo, a curto prazo. Neste caso, tem-se a contribuiçấo efetiva do lucro para o crescimento da empresa a longo prazo, uma vez que a receita total foi suficiente para cobrir os custos variáveis e os custos fixos e, ainda, sobrou um excedente, que pode ser utilizado como em investimento na unidade de produção.

Por outro lado, existem empresas que operam com prejuízo, a curto prazo. Teoricamente, esta posição é aceitável se o produtor conseguir cobrir os custos variáveis e parcela dos custos fixos. Assim, a diferença da receita em relaçáo aos custos variáveis, contribui para cobrir parte dos custos fixos. $\mathrm{Na}$ Figura 1, tais produtores estariam ocupando posiçôes ao longo da curva de custo marginal, situada entre os pontos A e B.

Por fim, os produtores que estáo operando na posição em que o preço é inferior ao $C V M e$ mínimo, náo devem continuar produzindo, pois a receita gerada náo é suficiente para cobrir os custos variáveis.

Nesta pesquisa, $80 \%$ dos produtores destacaram como um dos objetivos da empresa, aumentar a lucratividade via incremento da produtividade e redução de custos e os $20 \%$ restantes objetivam reduzir custo ou aumentar a produtividade.

Os produtores de grãos definem a margem de lucro como a diferença entre a receita total e os custos totais incompletos (consideram apenas os custos variáveis totais e parte dos custos fixos totais). Nenhum produtor está raciocinando com base nos custos totais de produção, pois náo incorporam os juros, depreciação e amortização das máquinas. Apenas o custo de oportunidade da terra é incorporado como custo fixo, uma vez que muitos produtores também arrendam terra para o cultivo de grãos. Esta é uma explicação para o sucateamento dos ativos produtivos utilizados nas unidades de produção de grãos entrevistadas.

Para facilitar a obtenção e análise dos dados sobre os custos de produção, trabalhou-se como indicador destes custos, em equivalente produto, ou seja, os valores monetários dos custos e das receitas foram transformados em unidades físicas do produto.

A Tabela 1 contém os dados sobre o desempenho das unidades produtivas com relaçáo à "margem de lucro", volume de vendas, custos de produção, participação no mercado e número de empregados. Para 40\% dos entrevistados (oito produtores), a "margem de lucro" diminuiu, e 30\% destacaram, que permaneceu a mesma. Por outro lado, 25\% (cinco entrevistados), informaram que conseguiram incrementar a "margem de lucro", combinando a utilização de inovaçóes tecnológicas, treinamento de mão de obra e novas formas de gestấo. Ressalta-se que os produtores náo incorporam todos os custos fixos na definição do lucro, portanto, esta "margem de lucro" pode lhes assegurar sobrevivência apenas a curto prazo. Neste caso, os $25 \%$ que obtiveram incremento da margem de lucro tendem sobreviver a longo prazo, ceteris paribus.

Analogamente, na percepção de 65\% (13 produtores) dos entrevistados, os custos de produçáo aumentaram. Com base nestas respostas, percebeu-se que as empresas estão conseguindo permanecer no mercado, em virtude do aumento do volume de vendas e da maior participaçáo no mercado, especialmente, por meio dos contratos estabelecidos com a Cargill, para o caso da soja e, no caso do milho, a venda para a Avispará - empresa produtora de ovos de galinha, entretanto, sem aumentar a margem de lucro.

Sete produtores informaram que a receita foi exatamente igual ao custo de produção, ou seja, não se obteve lucro, e nem

Tabela 1 - Desempenho das empresas do de grãos dos municípios de Belterra e Santarém, estado do Pará, safra 2008.

\begin{tabular}{lcccc}
\hline $\begin{array}{l}\text { Desempenho da } \\
\text { empresa }\end{array}$ & Diminuiu & Permaneceu & Aumentou & $\begin{array}{c}\text { Não } \\
\text { respondeu }\end{array}$ \\
\hline $\begin{array}{l}\text { Evolução da } \\
\text { "margem de lucro" }\end{array}$ & 8 & 6 & 5 & 1 \\
$\begin{array}{l}\text { Evolução do } \\
\text { volume de vendas } \\
\text { da empresa }\end{array}$ & 3 & 3 & 13 & 1 \\
$\begin{array}{l}\text { Os custos de } \\
\text { produção dos } \\
\text { produtos }\end{array}$ & 3 & 3 & 13 & 1 \\
$\begin{array}{l}\text { A participação de } \\
\text { sua empresa no } \\
\text { mercado }\end{array}$ & 4 & 6 & 9 & 1 \\
$\begin{array}{l}\text { O numero de } \\
\text { empregados da } \\
\text { empresa }\end{array}$ & 2 & 13 & 3 & 2 \\
\hline
\end{tabular}

Fonte: Pesquisa de campo. 
prejuízo. Portanto, estâo operando no ponto de equilíbrio. Vale ressaltar que, em princípio, a empresa opere em equilíbrio de curto prazo, com base nos custos variáveis, dado que os maiores gastos são com preparo de área, adubação, calagem e colheita. Por outro lado, caso o produtor não contabilize todos os custos tais como custos fixos, sobretudo o custo de oportunidade da terra, continuando a computando apenas os custos variáveis e parcela dos custos fixos, a unidade produtiva não apresentará perspectiva de sobrevivência a longo prazo, como revela a situação dos ativos fixos que se encontram além da vida útil. Como a receita não cobre todos os custos, a reposição dos ativos se torna impossível e, como consequência, a atividade perde competitividade e se torna inviável economicamente.

Conforme as informaçôes da Tabela 2, os custos médios de produção estimados pelos produtores, medido em equivalente de sacas de $60 \mathrm{~kg}$ de soja por hectare, relativo ao custeio da produçáo do ano 2008, foi de quarenta e uma sacas de $60 \mathrm{~kg}$ por hectare $\left(\mathrm{R} \$ 1.882,40 \mathrm{ha}^{-1}\right)$. Admitindo-se que a produção média da maioria dos produtores foi de quarenta e duas sacas de $60 \mathrm{~kg}$ por hectare, estes produtores estáo operando em uma situação em que a receita é suficiente para cobrir os custos variáveis e parte dos custos fixos. Em termos monetários, este ponto representa o valor de $\mathrm{R} \$ 2.019,78 \mathrm{ha}^{-1}$. Como apresentado na metodologia, estes produtores estáo operando entre os pontos $B\left(R \$ 1923,60 \mathrm{ha}^{-1}\right)$ e A $\left(\mathrm{R} \$ 2.164,05 \mathrm{ha}^{-1}\right) \mathrm{da}$ Figura 1, portanto, com prejuízo. Esta situação é justificada a curto prazo, mas a atividade náo se sustentará a longo prazo.

Na safra 2008, o orçamento realizado por uma empresa varejista da região só para produtos de dessecação, tratamento de sementes, herbicidas, inseticidas e fungicidas para produção de soja foi de $\mathrm{R} \$ 375,85 \mathrm{ha}^{-1}$. Este valor é similar ao informado pelos produtores (Tabela 2), que pagam oito sacas de $60 \mathrm{~kg}$ de soja por defensivos agrícolas. Considerando o preço de $\mathrm{R} \$$

Tabela 2 - Custos variáveis médios de produção em um hectare de soja em Belterra e Santarém, estado do Pará, safra 2008.

\begin{tabular}{lccc}
\hline \multirow{2}{*}{ Discriminação } & \multicolumn{3}{c}{ Safra 2008/2009 } \\
\cline { 2 - 4 } & Quantidade (kg) & Desvio Padrão (kg) & Custos (R\$) \\
\hline Adubos & 780 & 85,00 & 625,21 \\
Sementes & 180 & 4,50 & 144,28 \\
Defensivos & 480 & 9,60 & 384,74 \\
Mão de obra & 150 & 5,00 & 120,23 \\
temporária & 150 & 7,53 & 120,23 \\
Diesel & 300 & 13,52 & 240,47 \\
Colheita e & 300 & 18,06 & 240,47 \\
transporte & 120 & 11,21 & 96,19 \\
Arrendamento & & & \\
Calcário & &
\end{tabular}

Fonte: Pesquisa de campo.
48,09 a saca de $60 \mathrm{~kg}$ da soja, a aquisição de defensivos custa R\$384,74 ha-1 (Oliveira 2011).

De modo geral, com base nestes custos pode-se mostrar a dificuldade de entrada de novos empresários no arranjo, considerando, os gastos iniciais com adubação e calagem, bem como os custos fixos de arrendamento da terra, que podem chegar ao patamar de sete sacas de $60 \mathrm{~kg}$ de soja por hectare.

Considerando que os custos variáveis correspondem à maior parcela dos custos totais de produção da soja, o uso de tecnologias (especialmente as técnicas conservacionistas) é fundamental para a redução desses custos. Por exemplo, as informaçôes da Tabela 3 se referem às despesas de custeio da soja no sistema de plantio direto, que já representa cerca de $50 \%$ dos grãos plantados no Brasil, conforme a Companhia Nacional de Abastecimento (Conab 2010), e um sistema convencional com nível de produtividade similar ao obtido em Santarém e Belterra (Agrianual 2009; Oliveira 2011), no município de Balsas, estado do Maranhão, que apresentou margem de lucro negativa, após o pagamento de todos os seus custos, no valor de - R \$37,03 ha-1 (Agrianual 2009).

No sistema de plantio direto tem-se uma produtividade de $2.750 \mathrm{~kg} \mathrm{ha}^{-1}$. Já o sistema convencional apresentou uma produtividade menor, com $2.600 \mathrm{~kg} \mathrm{ha}^{-1}$ (Agrianual 2009). A produtividade média da soja em Santarém e Belterra, em cultivos com tecnologia convencional, foi de $2.400 \mathrm{~kg} \mathrm{ha}^{-1}$. Em pesquisa recente, Delate et al. (2003), Viana Filho et al. (2010) e Lichtenberg e Smith-Ramírez (2011) demonstraram, também, que a utilização de técnicas de produção conservacionistas, além de aumentar a produtividade, tendem a reduzir custo em relação às técnicas tradicionais.

Adicionalmente, verificou-se que além da menor produtividade alcançada no sistema convencional, há um maior custo variável em relação ao sistema de plantio direto. Este sistema, como também o de soja transgênica, apresenta maior rentabilidade em relação ao cultivo tradicional (Richetti e Reis 2003; Castro et al. 2006; Menegatti e Barros 2007; Lichtenberg e Smith-Ramírez 2011). Conforme dados da Tabela 3, percebe-se que o sistema de plantio direto utiliza

Tabela 3 - Despesas de custeio de dois sistemas de produção de soja, Balsas no estado do Maranhão, estado do Pará, safra 2008 (valores em reais de agosto de 2008).

\begin{tabular}{lcc}
\hline Discriminação & $\begin{array}{c}\text { Custos Conab } \\
\left(\mathrm{R} \$ \text { ha }^{-1}\right)\end{array}$ & $\begin{array}{c}\text { Custos Agrianual } \\
\left(\mathrm{R} \$ \mathrm{ha}^{-1}\right)\end{array}$ \\
\hline Operação com máquinas & 127,84 & 299,10 \\
Mão de obra temporária & 7,57 & 3,89 \\
Mão de obra fixa & 27,00 & - \\
Sementes & 80,00 & 127,85 \\
Fertilizantes & 441,82 & 634,00 \\
Defensivos & 143,64 & 215,81 \\
\hline
\end{tabular}

Fonte: CONAB (2010); AGRIANUAL (2009). 
1,5 vez menos defensivos (em relação a Santarém, este valor é menor, 2,62 vezes), 1,43 vez menos fertilizantes, 1,6 vez menos sementes e 2,34 vezes menos uso de maquinário, o que torna o sistema de plantio direto mais produtivo, rentável e ecologicamente mais sustentável. Ao analisar os resultados destes sistemas, percebe-se que o sistema adotado em Santarém e Belterra, em grande parte, é tecnicamente rudimentar. Considerando que, várias regióes produtoras de grãos adotam práticas conservacionistas, na região de fronteira, ainda predominam os modos de produção convencionais, de limitada eficiência. Estes sistemas, portanto, continuam atrasados em relação à fronteira tecnológica adotada nas regiôes produtoras de gráos, pois, conforme Chavas et al. (2010), ao longo dos anos os sistemas de produçáo, em funçấo do acúmulo de conhecimentos e da utilização de inovaçôes tecnológicas, vão ganhando maior eficiência diante dos desafios que a sociedade passa a exigir em relação à utilizaçâo de tecnologias que produzam baixo impacto sobre o meio ambiente.

Acontece que esse sistema de produçáo de soja praticado em Santarém e Belterra, com produtividade em torno das $2.580 \mathrm{~kg} \mathrm{ha}^{-1}$ parece de alta instabilidade de lucro, independente de onde é praticado. Como ilustração da produção obtida em outras regióes produtivas com sistema de produção similar, observou-se que a produtividade variou de $2.280 \mathrm{~kg} \mathrm{ha}^{-1}$ no Rio Grande do Sul (RS), passando por $2.580 \mathrm{~kg} \mathrm{ha}^{-1}$ no Maranhão (MA) e Bahia (BA), a $2.880 \mathrm{~kg}$ ha $^{-1}$ no Mato Grosso (MT) (Agrianual 2009). As informaçōes da Tabela 4 foram geradas com a incorporação de todos os custos fixos e variáveis e tecnologia tradicional, ou seja, não utilizam plantio direto. De acordo com esses resultados, ao longo de cinco anos, independentemente da produtividade e escala, em três deles o lucro foi negativo em todas essas regiōes produtivas.

Finalmente, de acordo com os dados da pesquisa, em conformidade com as informaçóes da Tabela 4, os sistemas de soja com tecnologia agronomicamente náo apropriada, com relação ao uso do solo, apresentaram prejuízo, no ano de 2008, em diversas regiôes produtivas do Brasil. Além disso, a rota inovativa desse sistema produtivo revela, recorrentemente, mais insucesso do que sucesso. Aplicando-se uma taxa desconto de 5\% ao ano, a esse fluxo de lucro apresentado no Agrianual (2009), apenas RS apresentaria um valor presente líquido positivo, no valor de $\mathrm{R} \$ 72,42$. Então, como os resultados sobre o desempenho desta tecnologia de produção náo sustentável estão disponíveis desde a introdução da soja na área de estudo, restriçôes poderiam ter sido adotadas contra a sua propagação na Amazônia.

\section{CONCLUSÕES}

A produção de soja em Santarém e Belterra é favorecida pelo porto da Cargill, mas o tipo de integraçáo estabelecido entre os produtores e a Cargill retira dos produtores grande parte da margem de lucro.

Os produtores de grãos de Santarém e Belterra estáo operando com prejuízo, por deficiência na determinação dos custos totais de produção.

Parte da vantagem competitiva proporcionada pelo Porto da Cargill é eliminada em funçáo do elevado custo de transporte dos insumos utilizados na produção da soja.

A soja cultivada em sistemas convencionais e ambientalmente nocivos, aumenta os custos com defensivos, fertilizantes, sementes e maquinário e vem gerando uma menor "margem de lucro" nos últimos anos.

\section{BIBLIOGRAFIA CITADA}

Agrianual. 2009. Anuário da Agricultura Brasileira. São Paulo: FNP Consultoria \& Comércio, 2005-2009.

Castro, S.H.; Reis, R.P.; Lima, A.L.R. 2006. Custos de produção da soja cultivada sob sistemas de plantio direto: estudos de multicaso no oeste da Bahia. Ciência Agrotecnologia, 30: 1146-1153.

Chavas, J-P.; Chambers, R.G.; Pope, R.D. 2010. Production economics and farm management: a century of contributions. American Journal of Agricultural Economics, 92: 356-375.

CONAB. Companhia nacional de abastecimento 2010. Indicadores agropecuários. 2010 (http://www.conab.gov.br). Acesso em 27/12/2010.

Delate, K.M.; Duffy, C.C.; A. Holste, H.F.; Wantate, N. 2003. An economic comparison of organic and conventional grain crops

Tabela 4 - Lucro operacional da lavoura de soja com tecnologia tradicional e produtividade em torno de $2.580 \mathrm{~kg}$ (43 sacas de 60 kg ha-1 $)$, estado do Pará, 2005/2009.

\begin{tabular}{lcccc}
\hline Ano & Lucro no RS & Lucro no MT & Lucro no MA & Lucro na BA \\
\hline 2005 & $-24,49$ & $-129,84$ & $-295,19$ & $-85,45$ \\
2006 & $-171,09$ & $-85,32$ & $-278,92$ & $-113,99$ \\
2007 & 238,01 & 229,89 & 177,28 & 160,43 \\
2008 & $-6,96$ & $-78,25$ & $-37,03$ & $-3,21$ \\
2009 & 65,15 & 58,92 & 39,42 & 61,08 \\
\hline
\end{tabular}

Fonte: AGRIANUAL (2005 a 2009). Valores deflacionados pelo IGPDI de agosto de 2008. 
in a long-term agroecological research (LTAR) site in Iowa. The American Journal of Alternative Agriculture, 18: 59-69.

Lichtenberg, E.; Smith-Ramírez, R. 2011. Slippage in conservation cost sharing. American Journal of Agricultural Economics, 93: 113-129.

Menegatti, A.L.A.; Barros, A. L. M. 2007. Análise comparativa dos custos de produçấo entre soja transgênica e convencional: um estudo de caso para o Estado do Mato Grosso do Sul. Revista de Economia e Sociologia Rural, 45: 163-183.

Nikerson, A.; Zenger, T.R. 2008. Envy, comparison costs, and the economic theory of the firm. Strategic Management Journal, 29: 1429-1449.

Oliveira, C.M. 2011. Governança e cooperação interinstitucional na dinamização de intervençôes em arranjos produtivos locais de lavoura no estado do Pará. Tese (Doutorado e Ciências Agrárias) - Universidade Federal Rural da Amazônia.

Pindyck, R.S.; Rubilfeld, D.L. 2010. Microeconomia. São Paulo: Pearson.

Richetti, A.; Reis, R.P. 2003. Fronteira de produção e eficiência econômica na cultura da soja no Mato Grosso do Sul. Revista de Economia e Sociologia Rural, 41: 45-61.

Santana, A.C. 2003. Análise da competitividade sistêmica da indústria de madeira no Estado do Pará. Revista de Economia e Agronegócio, 1: 205-230.
Santana, A.C. 2007. Índice de desempenho competitivo das empresas de polpa de frutas do Estado do Pará. Revista de Economia e Sociologia Rural, 45: 749-775.

Santana, A.C.; Filgueiras, G.C.; Rocha, C.F.G. 2006. Arranjos produtivos locais da BR-163: contribuiçóes ao planejamento estratégico territorial. Belém: ADA.

Santana, A.C.; Santana, A.L.; Nogueira, A.K.M. 2007. Retornos à escala e vantagem competitiva de custo das empresas de polpa de frutas no Estado do Pará. Amazônia: Ciência \& Desenvolvimento, 2: $187-203$.

Santana, A.C.; Santana, A.L.; Filgueiras, G.C. 2005. Identificação e análise de arranjos produtivos locais na BR-163: 2002 e 2003. Amazônia: Ciência \& Desenvolvimento, 1: 97-120.

Varela, L.B.; Santana, A.C.de. 2009. Aspectos econômicos da produção e do risco nos sistemas agroflorestais e nos sistemas tradicionais de produção agrícola em Tomé-Açu: 2001 a 2003. Revista Árvore, 33: 151-160.

Viana Filho, J.R; Stoffel, T.M.; Flores, M.B.V; Santos, B.P. 2010 Custo/benefício da cultura de soja: análise comparativa do uso de agrotóxicos orgânicos e 60 convencionais em Rondonópolis/ MT. Custos e @gronegócio on line, 6: 60-81.

Recebido em: 09-06-2011

Aceito em: 23-02-2012 
